\title{
Opportunistic infections in HIV-infected patients
}

\author{
CHAIRPERSON \\ STEPHEN D SHAFRAN, MD, FRCPC
}

$\mathrm{T}$ HE INITIAL RECOGNITION OF THE ACQUIRED IMMUNOdeficiency syndrome (AIDS) was made by the recognition of opportunistic infections $(1,2)$. Opportunistic infections are the 'AIDS-defining' event in approximately $75 \%$ of cases and eventually occur in virtually all AIDS patients. Eight opportunistic infections occur with high frequency in HIV-infected individuals (Table 1).

Of the eight common opportunistic infections, oral and esophageal candidiasis, mucocutaneous herpes simplex infection, and herpes zoster infections are easily managed and while there will be clinical trials of new azole antifungal drugs for candidiasis, and possibly clinical trials of new nucleoside analogues for herpes simplex and varicella-zoster infections, it is unlikely that these newer agents will offer substantial improvements over current therapies. The major unanswered questions in HIV-associated opportunistic infections relate to the other five opportunistic infections which will be discussed in turn.

\section{PNEUMOCYSTIS CARINII PNEUMONIA}

Pneumocystis carinii pneumonia (PCP) is the AIDSdefining condition in about $65 \%$ of cases and ultimately occurs in about $85 \%$ (3). Because of the current recommendations for both primary and secondary prophylaxis (4), it is anticipated that the incidence of PCP will diminish substantially in the future.

PCP treatment - Answered questions: Two studies have compared the relative efficacy of trimethoprim-sulphamethoxazole (TMP-SMZ) with that of intravenous pentamidine $(5,6)$. The earlier study of 40 patients found a higher survival rate in pentamidine-treated patients (95 versus $75 \%$ ), but this did not quite achieve significance $(P=0.09)(5)$. The results of this trial are difficult to interpret as approximately half of the patients

Workshop participants: W Cameron, I Chiu, G Evans, I Fong. G Garber, C Hankins, J Mendelson, R Morisset, P Phillips, I Salit, F Smail, G Taylor, $H$ Vellend

Correspondence: Dr Stephen Shafran, Division of Infectious Diseases, Department of Medicine, 2E4.11 Walter Mackenzie Health Sciences Centre, University of Alberta, Edmonton, Alberta T6G 2B7
TABLE 1

Common opportunistic infections in HIV-infected individuals

\begin{tabular}{lcc}
\hline Opportunistic infection & $\begin{array}{c}\text { AlDS- } \\
\text { defining } \\
\text { event }(\%)\end{array}$ & $\begin{array}{c}\text { Ultimate } \\
\text { prevalence } \\
(\%)\end{array}$ \\
\hline $\begin{array}{l}\text { Pneumocystis carinii pneumonia } \\
\text { Oral and esophagel candidiasis }\end{array}$ & 65 & 85 \\
Mucocutaneous herpes simplex & 2 & $? 80$ \\
infection & N/A & 60 \\
Herpes zoster & $1-2$ & $?$ \\
Mycobacterium avium complex & & 50 \\
infection & 2 & 10 \\
Cytomegalovirus disease & 3 & 10 \\
Cerebral toxoplasmosis & 2 & $5-13$ \\
Cryptococcosis & & \\
\hline
\end{tabular}

were crossed over from their initial assigned therapy due to drug toxicity.

In the second study of 70 patients, the survival in TMP-SMZ-treated patients was higher (86 versus $61 \%$ ) and this difference was statistically significant $(\mathrm{P}=0.03)$ (6). Furthermore, there were no cross-overs during this study. It appears, therefore, that TMP-SMZ may be more effective than pentamidine in subjects able to remain on therapy.

Medina et al (7) conducted a prospective randomized trial comparing TMP-SMZ with a combination of TMP and dapsone in AIDS-associated PCP. They found equivalent efficacy of the two therapies but lesser toxicity in the TMP and Dapsone group, of which 30\% experienced treatment limiting adverse effects, compared with $57 \%$ of patients treated with TMP-SMZ $(\mathrm{P}<0.025)$.

Two studies have compared the relative efficacy of intravenous pentamidine with that of aerosolized pentamidine $(8,9)$. Both studies demonstrated clearly that aerosolized pentamidine was less effective than intravenous pentamidine.

The role of adjunctive corticosteroids has also been studied in AIDS-associated PCP. Of five randomized con- 
trolled trials, three found a survival advantage for steroids including the two largest studies (10). A fourth study found improved oxygenation and long term exercise tolerance in the steroid-treated group (11). Only one of the five studies found no benefit from corticosteroids (12). An expert panel has recently issued a consensus statement recommending the use of adjunctive corticosteroids in AIDS-associated PCP when the initial room air $\mathrm{PO}_{2}$ is below $70 \mathrm{mmHg}$ (10).

Unanswered questions: The major unanswered questions in PCP treatment relate to the relative efficacy of therapies other than TMP-SMZ, TMP-dapsone and pentamidine. Specifically, the relative efficacy of clindamycin plus primaquine (13), trimetrexate (14), eflornithine (alpha-DFMO) (15), and newer agents such as piritrexim (16), 9-deazainosine (17) and 566C80 (18).

A trial comparing clindamycin and primaquine to TMP-SMZ has been proposed by Dr Emil Toma through the Canadian HIV Clinical Trials Network and it is hopeful that this trial will get underway in the near future. Trials with trimetrexate and 566C80 are currently ongoing in the United States through the AIDS Clinical Trial Group (ACTG).

PCP prophylaxis - Answered questions: The efficacy of TMP-SMZ in the primary prophylaxis of PCP in HIV-infected individuals has been examined in a placebo-controlled trial in patients with Kaposi's sarcoma (19). This study showed a potent effect of TMP$\mathrm{SMZ}$. The dose used was relatively high (one double strength tablet bid) and was associated with significant toxicity. A recent uncontrolled study using one double strength tablet three days a week was 100\% effective (20) indicating that lower doses of TMP-SMZ are also effective for PCP prophylaxis.

Aerosolized pentamidine has also been shown to be effective in PCP prophylaxis in a placebo-controlled trial (unpublished data) when given by ultrasonic nebulizer. Aerosolized pentamidine given by jet nebulizer is also effective, as demonstrated in a comparison of three different doses where the two higher dosing regimens were clearly superior to the lowest dose used, which has been considered by some to be a pseudoplacebo (21).

Controlled trials of other potential drugs for PCP prophylaxis have not been published, but uncontrolled favorable results have been reported using dapsone alone (22), fansidar (23) and clindamycin plus primaquine (24).

Unanswered questions: There is, as yet, no published study comparing the relative efficacy of the two most commonly used prophylactic treatments, namely TMPSMZ and aerosolized pentamidine. However, such a trial, in secondary prophylaxis only, has been completed by the ACTG (protocol 021). There also has been no comparison of the two major devices for nebulizing aerosolized pentamidine, namely the Fisoneb ultrasonic nebulizer and the Respirgard II jet nebulizer (several other nebulizers exist). Furthermore, the optimal neb- ulizer, dose and body positioning for delivery of aerosolized pentamidine remain to be established (25).

\section{MYCOBACTERIUM AVIUM COMPLEX INFECTION}

Mycobacterium avium complex (MAC) infection is the AIDS-defining event in fewer than $5 \%$ of cases (Federal Centre for AIDS data). However, MAC infection is diagnosed during life in 15 to $30 \%$ of AIDS patients and is found at autopsy in up to $53 \%$ of cases (26-28). While MAC infection is clearly a common late complication in AIDS, its contribution to mortality is questionable (29). Nevertheless, MAC infection can be an important cause of morbidity, causing fever, weight loss, diarrhea and, less frequently, focal disease in the biliary tract, lung and central nervous system (28). MAC isolates are characteristically resistant in vitro to most antimycobacterial agents $(26,28)$, recognizing that there are no clearly accepted standards for susceptibility testing for nontuberculous mycobacteria.

Answered questions: There are essentially no answered questions in this area.

Unanswered questions: There is considerable debate as to the merits of therapy for MAC infection due to the following factors.

- The contribution of MAC to AIDS mortality is minimal.

- MAC isolates are multiresistant in vitro.

- In a number of patients, MAC infection is diagnosed at such an advanced stage of AIDs that treatment may be inappropriate.

- The addition of three or four drugs to patients who generally are already taking antiretroviral, anti-PCP and anticandidal therapy is problematic.

- The results of many of the early reports of treatment have been unfavorable.

No controlled clinical trials in the treatment of MAC infection have ever been published, although a pilot study of clarithromycin monotherapy has been reported in abstract form (30). The initial reports of the results of treating MAC infection in AIDS patients were unfavorable (31-33); however, three more recent reports of combination drug therapy have been very encouraging (34-36). For this reason, the pendulum appears to be swinging towards treating most symptomatic patients.

In January 1991, the Canadian HIV Trials Network approved a multicentre trial comparing two different regimens of combination therapy for MAC bacteremia. It was anticipated that the trial would start in the summer of 1991.

In the United States, a trial is proposed to compare the combination of rifabutin, ethambutol and clofazimine to ethambutol and clofazimine without rifabutin. Furthermore, it is anticipated that trials using clarithromycin will commence within the next year, based on the encouraging pilot study from France noted above (30).

Finally, there is presently an ongoing multicentre 
United States/Canada double-blinded trial evaluating the efficacy of rifabutin monotherapy in the prevention of MAC infection in AIDS patients with CD4 lymphocyte counts below $200 \times 10^{6} / \mathrm{L}$, who have no previous history of mycobacterial infection.

\section{CYTOMEGALOVIRUS INFECTION}

Nearly all HIV infected patients are cytomegalovirus (CMV) seropositive (37). Furthermore, isolation of CMV from a variety of body sites in the absence of clear disease occurs commonly, particularly in association with marked CD4 lymphopenia. Although CMV has been isolated from nearly every organ in AIDs patients, definite evidence of disease occurs most commonly in the retina and bowel $(37,38)$. CMV retinitis occurs in 5 to $10 \%$ of AIDs patients and CMV enteritis is about half as prevalent $(37,38)$. It is unusual for both retinitis and enteritis to occur in the same individual $(37,38)$.

Answered questions: In the case of retinitis, intravenous ganciclovir has been approved for use in both the United States and Canada on the basis of open trials demonstrating efficacy (39). Placebo-controlled trials have not been conducted because of an impression that disease invariably progresses in the absence of therapy. While approximately $85 \%$ of patients with CMV retinitis have a favorable response to ganciclovir, it is clear, that the majority of individuals will relapse after ganciclovir therapy necessitating maintenance therapy $(37,38,40)$; however, even with maintenance therapy, deterioration occurs in at least $50 \%$ of patients $(38,40)$. Foscarnet has also been shown to be effective for CMV retinitis in uncontrolled trials $(41,42)$.

Unanswered questions: The obvious unanswered question is the comparison of the relative efficacy and toxicity of ganciclovir and foscarnet. Such a study is underway in the United States. The same trial was approved by the Canadian HIV Trials Network, but insufficient funding was available. A similar study in only 40 patients was conducted in England and found similar response rates to the two drugs (43).

The addition of immunoglobulin (either polyclonal or CMV hyperimmune) to ganciclovir has improved the response of CMV pneumonia in bone marrow transplant recipients $(44,45)$. The role of additional immunoglobulin therapy in CMV retinitis is unclear, but a pilot study suggested a lack of efficacy (46).

Intravitreal ganciclovir therapy has been successful $(47,48)$, but generally has been reserved for patients who experienced excessive myelotoxicity with systemic ganciclovir. The relative efficacy of the intravitreal versus the intravenous route has not been compared.

There are presently no published controlled trials of effective therapy for HIV-associated CMV enteritis, although there are anecdotal reports of favorable responses with ganciclovir $(37,38)$. In bone marrow transplant recipients, ganciclovir was no more effective than placebo in relieving symptoms of proven CMV enteritis, despite a definite antiviral effect (49). A placebo-controlled trial of ganciclovir for CMV colitis in 62 AIDS patients has been presented in abstract form (50). There was a marked antiviral effect and a modest but not statistically significant clinical benefit favouring ganciclovir.

\section{CEREBRAL TOXOPLASMOSIS}

Cerebral toxoplasmosis occurs in approximately $10 \%$ of AIDS patients (51). Nearly all cases occur in patients seropositive for Toxoplasma gondii of whom approximately 30\% will develop toxoplasmosis $(51,52)$. Answered questions: It is clear that most AIDS patients with cerebral toxoplasmosis respond favorably to pyrimethamine and sulphadiazine therapy (51-55). However, most patients successfully treated will relapse if therapy is stopped altogether (53-55); therefore, maintenance therapy with reduced dose pyrimethamine and sulphadiazine is the standard treatment $(51,53,56)$.

Clindamycin with or without pyrimethamine is also effective in the treatment of cerebral toxoplasmosis (57-59). The relative efficacy of sulphadiazine plus pyrimethamine versus clindamycin plus pyrimethamine for cerebral toxoplasmosis was evaluated by the California Collaborative Treatment Group (60). The two regimens did not appear to differ in efficacy, although the sample size precludes a definitive statement of equivalence.

Unanswered questions: A major unanswered question relates to the role of prophylaxis in toxoplasma seropositive patients. It has been argued that prophylaxis is likely to be effective (61), and should be evaluated (61, 62). At this point, such a trial has not been published.

A potential problem for any study in cerebral toxoplasmosis will be whether brain biopsy is required for diagnosis, since many clinicians do not routinely recommend confirming the diagnosis by brain biopsy (63). This issue must be clearly addressed in any such trial.

\section{CRYPTOCOCCOSIS}

Cryptococcosis is reported in 5 to $13 \%$ of AIDS cases (64), with a lower incidence likely if oral azole therapy is initiated early to treat mucosal candidiasis.

Therapy - Answered questions: Two major trials have compared the efficacy of amphotericin B with that of fluconazole $(65,66)$. Larsen et al $(65)$ compared the combination of amphotericin B at a dosage of 0.7 $\mathrm{mg} / \mathrm{kg} /$ day, and flucytosine $150 \mathrm{mg} / \mathrm{kg} /$ day with fluco nazole $400 \mathrm{mg} /$ day and found that six of six amphotericin-treated patients had sterile cerebrospinal fluid at week 10, compared with five of 14 treated with fluconazole, a difference which was highly significant. As well, sterilization of the cerebrospinal fluid occurred significantly more rapidly with amphotericin B.

In contrast, the presently unpublished study conducted jointly by the Mycosis Study Group of the National Institute of Allergic and Infectious Diseases and the ACTG showed comparable efficacy of the two treatments. 
Secondary prophylaxis: Fluconazole at a dose of 200 $\mathrm{mg} /$ day reportedly is more effective than either placebo or amphotericin B given intravenously at a dosage of 1 $\mathrm{mg} / \mathrm{kg}$ once a week in the secondary prophylaxis of cryptococcal infection in AIDS patients $(67,68)$.

Treatment - Unanswered questions: The relative efficacy of amphotericin B versus triazoles is not entirely resolved, particularly as higher doses of triazoles than those used in previous trials may be tolerated. Furthermore, even if amphotericin B is the initial agent used, it may be possible to switch to triazoles at an earlier point than 10 weeks, perhaps dictated by a specified period after initial sterilization.

Flucytosine's role in the treatment of cryptococcosis remains controversial. In a frequently cited study conducted in the pre-AIDS era, the combination of amphotericin B plus flucytosine was more effective than amphotericin B alone (69). This study has been criticized, however, because of the low dosage of amphotericin $B$ chosen in both arms, and because the efficacy of the amphotericin B monotherapy arm was lower than historic controls (70). A similar trial has not been conducted in AIDS patients. However, uncontrolled data from San Francisco do not suggest that combination therapy is more effective than amphotericin B monotherapy (71). Also, the myelosuppressive properties of flucytosine make it difficult to use in AIDS patients.

The role of liposome-encapsulated amphotericin B in human cryptococcosis has not been evaluated, but such therapy is effective in murine cryptococcosis (72). Prophylaxis: Whereas triazole antifungals such as itraconazole and saperconazole may prove to be as effective as fluconazole for secondary prophylaxis of cryptococcosis, is extremely doubtful that they will prove to be more effective.

\section{PROPOSED CLINICAL TRIALS}

On the basis of the above review, and extensive discussions in the workshop, the working group proposed two clinical trials.

ADDENDUM: Dr Shafran wishes to stress that AIDs is a rapidly changing field and that the manuscript was written in April 1991; thus, significant changes have occurred in this area since that time.

\section{REFERENCES}

1. Gottlieb MS, Schroff R, Schanker HM, et al. Pneumocystis carinii pneumonia and mucosal candidiasis in previously healthy homosexual men. Evidence of a new acquired cellular immunodeficiency. N Engl J Med 1981:305:1425-31.

2. Masur H, Michelis MA, Greene JB, et al. An outbreak of community-acquired Pneumocystis carinii pneumonia. Initial manifestation of cellular immune dysfunction. N Engl J Med 1981;305:1431-8.

3. Murray JF, Mills J. Pulmonary infectious complications of human immunodeficiency virus infection. Part II. Am Rev Respir Dis 1990;141:1582-98.
Trial 1: 'A prospective randomized comparative trial of TMP plus dapsone versus aerosolized pentamidine for the prevention of PCP and toxoplasmosis.' The purpose of this trial is to answer two questions. First, to determine the relative efficacy of aerosolized pentamidine versus an orally absorbed systemic therapy for PCP prevention. TMP plus dapsone was chosen over TMPSMZ because TMP plus dapsone was shown to be better tolerated in a PCP treatment study (7), and it was felt that it was less likely that such a trial was taking place elsewhere.

The second is to determine whether there is a role for prophylactic therapy for toxoplasmosis in HIV-infected individuals who are toxoplasma-seropositive. Although pyrimethamine plus sulphadiazine is the best studied treatment for toxoplasmosis, TMP plus dapsone was selected for the following reasons: this selection would facilitate answering two important clinical questions with one study design; and this combination is known to be effective in vitro and in animal models of toxoplasmosis $(73,74)$.

Therefore, in order to conduct this study properly, it was acknowledged that toxoplasma serology would be done in a single reference laboratory and that patients would be stratified according to their toxoplasma serological status. Patients were then to be randomly allocated 1:1 to aerosolized pentamidine versus TMP plus dapsone.

Trial 2: The working group felt frustrated by the clinical problem of CMV enteritis. Clinicians reported a perceived pressure to administer ganciclovir therapy in order to feel that something is being done, despite a lack of efficacy data. A consensus regarding the study design was not finalized. It was acknowledged that a placebocontrolled trial is indeed ethical, but might be impossible to carry out. Alternative trials included a comparison of ganciclovir with foscarnet, or a comparison of ganciclovir alone with ganciclovir plus either CMV immune globulin or polyclonal intravenous immunoglobuin.

4. Masur H, Allegra C, Armstrong D, et al. Guidelines for prophylaxis against Pneumocystis carinii pneumonia for persons infected with human immunodeficiency virus. MMWR 1989;38:1-9.

5. Wharton JM, Coleman DL, Wofsy CB, et al. Trimethoprim-sulfamethoxazole or pentamidine for Pneumocystis carinii pneumonia in the acquired immunodeficiency syndrome. Ann Intern Med 1986;105:37-44.

6. Settler FR, Cowan R, Nielsen DM, Ruskin J. Trimethoprim-sulfamethoxazole compared with pentamidine for treatment of Pneumocystis carinii pneumonia in the acquired immunodeficiency syndrome: A prospective, noncrossover study. Ann Intern Med 1988;109:280-7.

7. Medina I, Mills J, Leoung C, et al. Oral therapy for Pneumocystis carinii pneumonia in the acquired immunodeficiency syndrome. A controlled trial of 
trimethoprim-sulfamethoxazole versus trimethoprimdapsone. N Engl J Med 1990;323:776-82.

8. Soo Hoo GW, Mohsenifar Z, Meyer RD. Inhaled or intravenous pentamidine therapy for Pneumocystis carinii pneumonia in AIDS: A randomized trial. Ann Intern Med 1990; 113:195-202.

9. Conte JE, Chernoff D, Feigal DW Joseph P, McDonald C, Golden JA. Intravenous or inhaled pentamidine for treating Pneumocystis carinii pneumonia in AIDS: A randomized trial. Ann Intern Med 1990;113-203-9.

10. Masur H, Meier P, McCutchan JA, et al. Special report: Consensus statement on the use of corticosteroids as adjunctive therapy for pneumocystis pneumonia in the acquired immunodeficiency syndrome. N Engl J Med 1990;323:1500-5.

11. Montaner JSG, Lawson LM, Levitt N, Belzberg A, Schechter MT, Ruedy J. Corticosteroids prevent early deterioration in patients with moderately severe Pneumocystis carinii pneumonia and the acquired immunodeficiency syndrome (ADS). Ann Intern Med 1990;113:14-20.

12. Clement M, Edison R, Turner J, et al. Corticosteroids as adjunctive therapy in severe Pneumocystis carinii pneumonia: A prospective placebo-controlled trial. Am Rev Respir Dis 1989;139:A250. (Abst)

13. Toma E, Poisson M, Phaneuf D, Fournier S, Morisset R, Vega C. Clindamycin with primaquine for Pneumocystis carinii pneumonia. Lancet 1989;i:1046-8.

14. Allegra CJ, Chabner BA, Tuazon CU, et al. Trimetrexate for the treatment of Pneumocystis carinii pneumonia in patients with the acquired immunodeficiency syndrome. N Engl J Med 1987;317:978-85.

15. Golden JA, Sjoerdsma A, Santi DV. Pneumocystis carinii pneumonia treated with alpha-difluoromethylornithine. A prospective study among patients with the acquired immunodeficiency syndrome. West $J$ Med 1984; 141:613-23.

16. Queener SF, Bartlett MS, Jay MA, Durkin MM, Smith JW. Activity of lipid-soluble inhibitors of dihydrofolate reductase against Pneumocystis carinii in culture and in a rat model of infection. Antimicrob Agents Chemother 1987;31:1323-7.

17. Smith JW, Bartlett MS, Queener MM, et al. Pneumocystis carinii pneumonia therapy with 9-deazainosine in rats. Diagn Microbiol Infect Dis 1987;7:113-8.

18. Hughes WT, Kennedy W, Shenep J, et al. Safety and pharmacokinetics of 566C80, a hydroxynaphthoquinone with anti-Pneumocystis carinii activity: A phase I study in human immunodeficiency virus (HIV)-infected men. J Infect Dis 1991;163:843-8.

19. Fischl MA, Dickinson GM, LaVoie L. Safety and efficacy of sulfamethoxazole and trimethoprim chemoprophylaxis for Pneumocystis carinii pneumonia in AIDS. JAMA 1988:259:1185-9.

20. Ruskin J, LaRiviere M. Low-dose co-trimoxazole for prevention of Pneumocystis carinii pneumonia in human immunodeficiency virus disease. Lancet 1991;337:468-71.

21. Leoung GS, Feigal DW, Montgomery AB, et al. Aerosolized pentamidine for prophylaxis against Pneumocystis carinii pneumonia. N Engl J Med 1990;323:769-75.

22. Lucas CR, Sandland AM, Mijch A, Simpson JM. Primary dapsone chemoprophylaxis for Pneumocystis carinii pneumonia in immunocompromised patients infected with the human immunodeficiency virus. Med J Aust 1989;151:30-3.

23. Gottlieb MS, Knight S, Mitsuyasu R, Weisman J, Roth M, Young LS. Prophylaxis of Pneumocystis carinii infections in AIDS with pyrimethamine-sulfadoxine. Lancet 1984;ii:398-9.

24. Kay R, DuBois RE. Clindamycin/primaquine therapy and secondary prophylaxis against Pneumocystis carinii pneumonia in patients with alDs. South Med J 1990;83:403-4.

25. Baskin MI, Abd AG, Ilowite JS. Regional deposition of aerosolized pentamidine: Effects of body position and breathing pattern. Ann Intern Med 1990;113:677-83.

26. Hawkins CC, Gold JWM, Whimbey E, et al. Mycobacterium avium complex infections in patients with the acquired immunodeficiency syndrome. Ann Intern Med 1986;105:184-8.

27. Dawson DJ. Infection with Mycobacterium avium complex in Australian patients with AIDS. Med J Aust 1990; 153:466-8

28. Jacobson MA. Mycobacterial diseases: Tuberculosis and Mycobacterium avium complex. Infect Dis Clin North Am 1988:2:465-74

29. Chaisson RE, Hopewell PC. Mycobacteria and AIDS mortality. Am Rev Respir Dis 1989;139:1-3. (Edit)

30. Dautzenberg B, Legris S, Truffot C, et al. Double blind study of efficacy of clarithromycin versus placebo in Mycobacterium avium-intracellulare infection in AIDS patients. Am Rev Respir Dis 1990:141:A615. (Abst)

31. Greene JB, Sidhu GS, Lewin S, et al. Mycobacterium avium-intracellulare: A cause of disseminated life threatening infection in homosexuals and drug abusers. Ann Intern Med 1982;97:539-46.

32. Hawkins CC, Gold TWM, Whimbey E, et al. Mycobacterium avium complex infections in patients with acquired immunodeficiency syndrome. Ann Intern Med 1986; 105:184-8

33. Masur H, Tuazon C, Gill V, et al. Effect of combined clofazimine and ansamycin therapy on Mycobacterium avium-Mycobacterium intracellulare bacteremia in patients with AIDS. J Infect Dis 1987; 155:127-9.

34. Agins BD, Berman DS, Spicehandler D, El-Sadr W, Simberkoff MS, Rahal JJ. Effects of combined therapy with ansamycin, clofazimine, ethambutol, and isoniazid for Mycobacterium avium infection in patients with AIDS. Infect Dis 1989;159:784-7.

35. Hoy J, Mijch A, Sandland M, Grayson L, Lucas R, Dwyer B. Quadruple-drug therapy of Mycobacterium avium-intracellulare bacteremia in AIDS patients. J Infect Dis 1990;161:801-5.

36. Chiu J, Nussbaum J, Bozzette S, et al. Treatment of disseminated Mycobacterium avium complex infection in AIDS with amikacin, ethambutol, rifampin, and ciprofloxacin. Ann Intern Med 1990;113:358-61.

37. Jacobson MA, Mills J. Serious cytomegalovirus disease in the acquired immunodeficiency syndrome (ADS). Ann Intern Med 1988;108:585-94.

38. Jacobson MA, O'Donnell JJ, Porteous D, Brodie HR, Feigal D, Mills J. Retinal and gastrointestinal disease due to cytomegalovirus in patients with the acquired immune deficiency syndrome: Prevalence, natural history, and response to ganciclovir therapy. Q J Med 1988:254:473-86.

39. Holland GN, Buhles WC Jr, Mastre B, Kaplan HJ, the UCLA CMV Retinopathy Study Group. A controlled retrospective study of ganciclovir treatment for cytomegalovirus retinopathy. Arch Ophthalmol 1989; 107:1759-66.

40. Bloom JN, Palestine AG. The diagnosis of cytomegalovirus retinitis. Ann Intern Med 1988; 109:963-9

41. Walmsley SL, Chew E, Read SE, et al. Treatment of 
cytomegalovirus retinitis with trisodium phosphonoformate hexadydrate (foscarnet). J Infect Dis 1988;157:569-72.

42. Jacobson MA, O'Donnell JJ, Mills J. Foscarnet treatment of cytomegalovirus retinitis in patients with the acquired immunodeficiency syndrome. Antimicrob Agents Chemother 1989;33:736-41.

43. Graeme M, Mathalone B, Gazzard B. An open randomized comparative study of foscarnet and ganciclovir in the treatment of CMV retinitis. Presented at the VIth International Conference on AIDS, 1990. (Abst)

44. Emanuel D, Cunningham I, Jules-Elysee K, et al. Cytomegalovirus pneumonia after bone marrow transplantation successfully treated with the combination of ganciclovir and high-dose intravenous immune globulin. Ann Intern Med 1988;109:777-82.

45. Reed EC, Bowden RA, Dandliker PS, Lilleby KE, Meyers JD. Treatment of cytomegalovirus pneumonia with ganciclovir and intravenous cytomegalovirus immunoglobulin in patients with bone marrow transplants. Ann Intern Med 1988;109:783-8.

46. Jacobson MA, O'Donnell JJ, Rousell R, Dionian B, Mills J. Failure of adjunctive cytomegalovirus intravenous immune globulin to improve efficacy of ganciclovir in patients with acquired immunodeficiency syndrome and cytomegalovirus retinitis: A phase 1 study. Antimicrob Agents Chemother 1990;34:176-8.

47. Ussery FM III, Gibson SR, Conklin RH, Piot DF, Stool EW, Conklin AJ. Intravitreal ganciclovir in the treatment of AIDS-associated cytomegalovirus retinitis. Ophthalmol 1988:95:640-8.

48. Heinemann MH. Long-term intravitreal ganciclovir therapy for cytomegalovirus retinopathy. Arch Ophthalmol 1989;107:1767-72.

49. Reed EC, Wolford JL, Kopecky KJ, et al. Ganciclovir for the treatment of cytomegalovirus gastroenteritis in bone marrow transplant patients. A randomized, placebocontrolled trial. Ann Intern Med 1990;112:505-10.

50. Dietrich D, Kotler D, Busch D, et al. Randomized, placebo-controlled study of ganciclovir treatment of cytomegalovirus (CMV) colitis in AIDs patients.

Presented at the VIth International Conference on AIDS, 1990. (Abst)

51. Israelski DM, Remington JS. Toxoplasmic encephalitis in patients with AIDs. Infect Dis Clin North Am 1988;2:429-45.

52. Luft BJ, Brooks RC, Conley FK, McCabe RE, Remington JS. Toxoplasmic encephalitis in patients with acquired immune deficiency syndrome. JAMA 1984;252:913-7.

53. Navia BA, Petito CK, Gold JWM, Cho, ES, Jordan BD, Price RW. Cerebral toxoplasmosis complicating the acquired immune deficiency syndrome: Clinical and neuropathological findings in 27 patients. Ann Neurol 1986:9:224-38.

54. Wanke C, Tuazon CU, Kovacs A, et al. Toxoplasma encephalitis in patients with acquired immune deficiency syndrome: Diagnosis and response to therapy. Am J Trop Med Hyg 1987;36:509-16.

55. Haverkos HW, The TE Study Group. Assessment of therapy for toxoplasma encephalitis. Am J Med 1987;82:907-14.

56. Leport C, Raffi F, Matheron SS, et al. Treatment of central nervous system toxoplasmosis with pyrimethamine/sulfadiazine combination in 35 patients with the acquired immunodeficiency syndrome. Am J Med 1988;84:94-100.
57. Hofflin JM, Remington JS. Clindamycin in a murine model of toxoplasmic encephalitis. Antimicrob Agents Chemother 1987:31:492-6.

58. Rolston KVI, Hoy J. Role of clindamycin in the treatment of central nervous system toxoplasmosis. Am J Med 1987:83:551-4.

59. Dannemann BR, Israelski DM, Remington JS. Treatment of toxoplasmic encephalitis with intravenous clindamycin. Arch Intern Med 1988;148:2477-82.

60. Dannemann BR, McCutchan JA, Israelski DM, et al. Treatment of toxoplasmic encephalitis in patients with AIDS: A randomized trial comparing pyrimethamine plus clindamycin to pyrimethamine plus sulfonamides. Presented at the 30th ICAAC, 1990. (Abst)

61. Rose DN. Prevention of toxoplasma activation among immunocompromised patients: A decision analysis. Presented at the VIth International Conference on AIDS, 1990. (Abst)

62. Girard PM, Pocidalo JJ, Murray JF. Primary prophylaxis against common infectious diseases in persons with human immunodeficiency virus infection. Am Rev Respir Dis 1991; 143:447-50.

63. Cohn JA, McMeeking A, Cohen W, Jacobs J, Holzman RS. Evaluation of the policy of empiric treatment of suspected toxoplasma encephalitis in patients with the acquired immunodeficiency syndrome. Am J Med 1989:86:521-7.

64. Dismukes WE. Cryptococcal meningitis in patients with AIDS. J Infect Dis 1988;157:624-8.

65. Larsen RA, Leal MAE, Chan LS. Fluconazole compared with amphotericin B plus flucytosine for cryptococcal meningitis in AIDS: A randomized trial. Ann Intern Med 1990;113:183-7.

66. Data on file, Pfizer Central Research, Groton, Connecticut.

67. Bozzette SA, Larsen RA, Chill J, et al. A placebocontrolled trial of maintenance therapy with fluconazole after treatment of cryptococcal meningitis in the acquired immunodeficiency syndrome. N Engl J Med 1991;324:580-4.

68. Powderly W, Cloud MSG, Dismukes W, et al. Fluconazole versus amphotericin $\mathrm{B}$ as maintenance therapy for prevention of relapse of AIDS-associated cryptococcal meningitis. Presented at the 30th ICAAC, 1990. (Abst)

69. Bennett JE, Dismukes WE, Duma RJ, et al. A comparison of amphotericin B alone and combined with flucytosine in the treatment of cryptococcal meningitis. N Engl J Med 1979;301:126-31.

70. Sabetta JR, Andriole V. Cryptococcal infection of the central nervous system. Med Clin North Am 1985;69:333-44

71. Chuck SL, Sande MA. Infections with Cryptococcus neoformans in the acquired immunodeficiency syndrome. N Engl J Med 1989:32 1:794-9.

72. Graybill JR, Craven PC, Taylor RL, Williams DM, Magee WE. Treatment of murine cryptococcosis with liposome-associated amphotericin B. J Infect Dis 1982:145:748-52.

73. Allegra CJ, Boarman D, Kovacs JA, et al. Interaction of sulfonamide and sulfone compounds with Toxoplasma gondii dihydropteroate synthase. J Clin Invest 1990;85:371-9.

74. Derouin F, Piketty C, Chastang C, Chau F, Rouveix B, Pocidalo JJ. Antitoxoplasma effects of dapsone alone and combined with pyrimethamine. Antimicrob Agents Chemother 1991:35:252-5. 


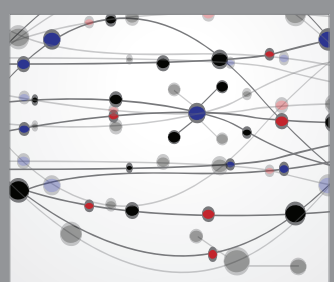

The Scientific World Journal
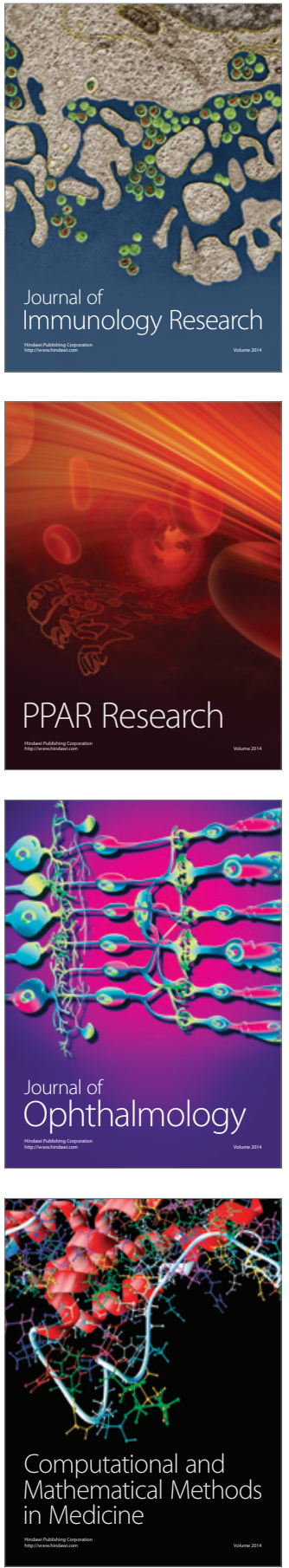

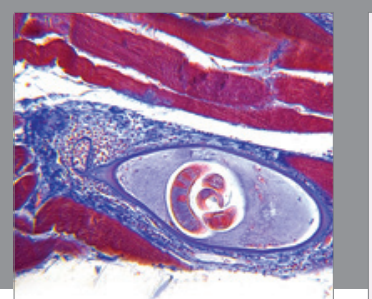

Gastroenterology Research and Practice

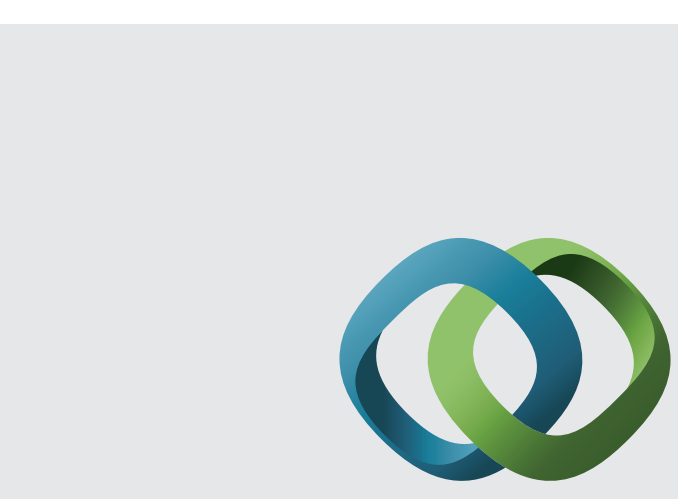

\section{Hindawi}

Submit your manuscripts at

http://www.hindawi.com
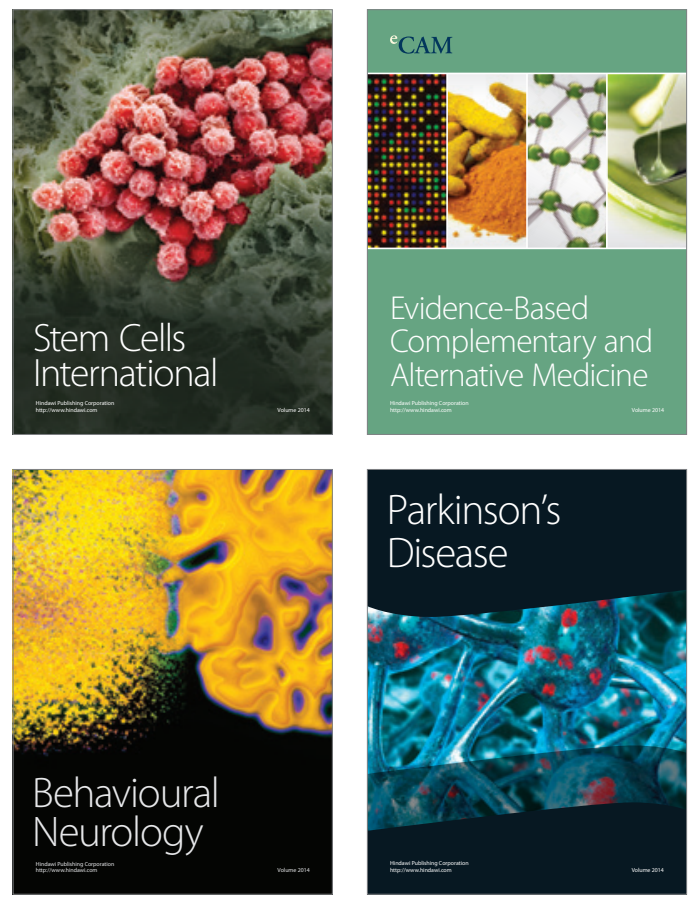
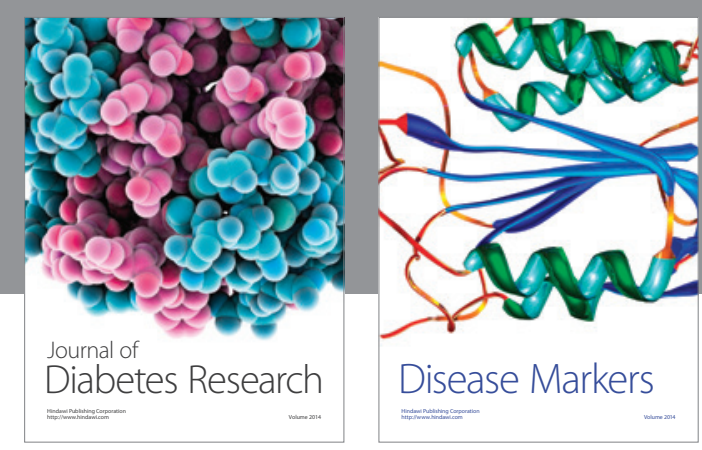

Disease Markers
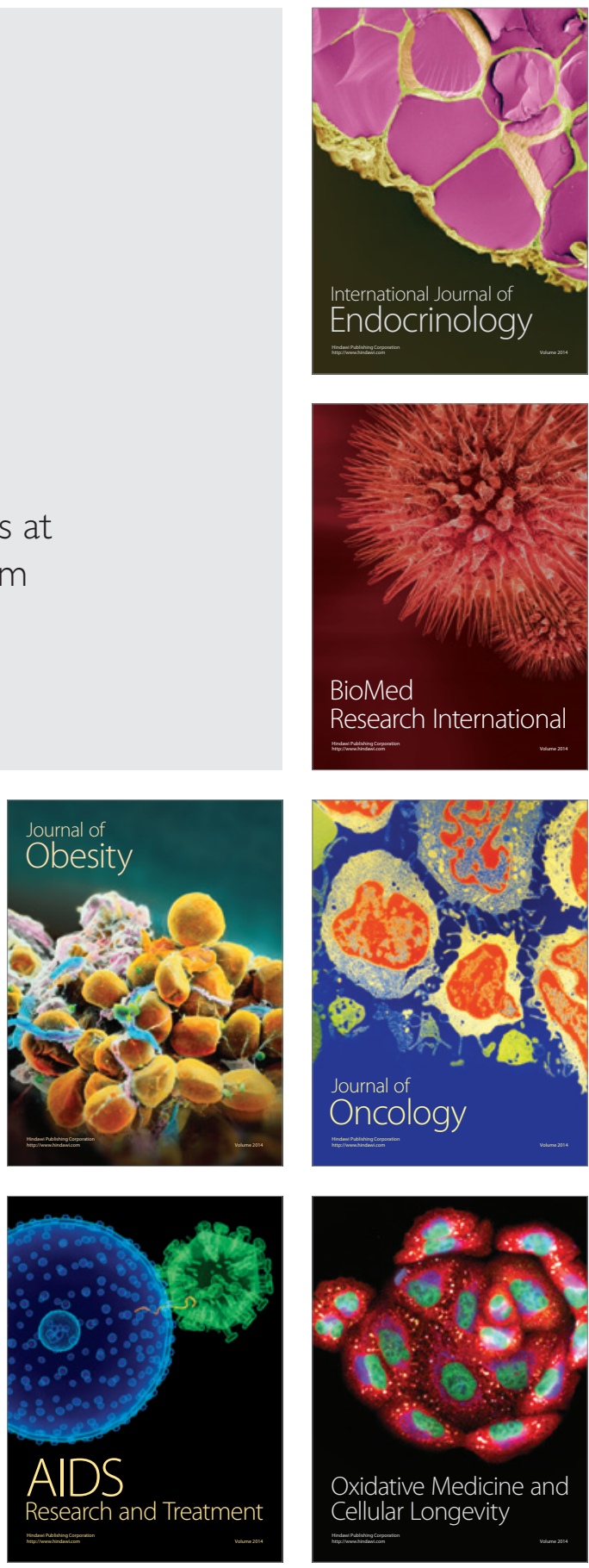